\title{
Impact of Serum Amylase Level in the Outcome of Acute Organophosphorus Poisoning: 2-Year Cross-Sectional Study at Rural Teaching Hospital
}

\author{
Aniket Patil ${ }^{1}$ Sunil Kumar ${ }^{1} \quad$ Anil Inamdar $^{1}$ Sourya Acharya ${ }^{1} \quad$ Anil Wanjari $^{1}$ Shilpa Bawankule ${ }^{1}$ \\ Sachin Agrawal ${ }^{1}$ Tushar Sontakke ${ }^{1}$ \\ ${ }^{1}$ Department of Medicine, Jawaharlal Nehru Medical College, \\ Address for correspondence Sunil Kumar, MD, PhD, Department of \\ DattaMeghe Institute of Medical Science (Deemed to be University) \\ Sawangi Meghe, Wardha, Maharashtra, India \\ Medicine, Jawaharlal Nehru Medical College, DattaMeghe Institute of \\ Medical Science (Deemed to be University) Sawangi Meghe, Wardha, \\ Maharashtra 442004, India (e-mail: sunilkumarmed@gmail.com).
}

J Lab Physicians 2022;14:1-5.

\begin{abstract}
Keywords

- serum amylase

- organophosphorus poisoning

- outcome

- serum acetylcholinesterase

Introduction Prompt recognition and aggressive management of acute intoxication due to organophosphorus poisoning are essential to minimize the morbidity and mortality. The present study was undertaken to know the prognosis and outcome of organophosphorus poisoning patients with the estimation of low-cost enzymes like the serum amylase level in a population with financial constraints.

Methods In this cross-sectional study, we had enrolled 100 cases that had a history of exposure to organophosphorus compounds, and the serum amylase level was measured in all the patients. We assessed the outcome of all the patients in the form of discharge, need of ventilators, intensive care unit stay, and death.

Results The mean serum amylase level in discharge patients was $335.40 \pm 192.45$, and in the patients who died it was $843.37 \pm 22.60$. It was significant to predict the outcome ( $t$-value $7.07, p$-value 0.0001 , statistically significant).

Conclusion Serum amylase level shows significant correlation with clinical outcomes in organophosphorus poisoning.
\end{abstract}

\section{Introduction}

Poisons are subtle and silent weapons that can be easily used without violence and often without arousing suspicion. In India, which is predominantly an agrarian country, organophosphorus (OP) poisoning has become a common modality of poisoning because of its vast use, easy availability, and affordability over the counter. ${ }^{1}$ The importance of pesticides in India can be understood from the fact that agriculture is a major component of the Indian economy: it contributes to $22 \%$ of the nation's gross domestic product and is the liveli- hood of nearly $70 \%$ the country's workforce. ${ }^{2}$ According to Data from National Crime Bureau of India, 5,915 and 7,060 cases of insecticide/pesticide poisoning deaths were reported among 29 states and 7 union territories in the year 2014 and 2015, respectively. Maharashtra state is the second highest reporting 1,050 and 1,042 cases of insecticide/pesticide poisoning death case after Madhya Pradesh in the year 2014 and 2015, respectively. Cholinesterase assays can act as a useful guide for the clinicians to provide streamline management for better prognosis. Diagnosis of OP poisoning should ideally be confirmed with an published online September 8, 2021
DOI https://doi.org/ 10.1055/s-0041-1734015. ISSN 0974-2727. (c) 2021. The Indian Association of Laboratory Physicians. All rights reserved.

This is an open access article published by Thieme under the terms of the Creative Commons Attribution-NonDerivative-NonCommercial-License, permitting copying and reproduction so long as the original work is given appropriate credit. Contents may not be used for commercial purposes, or adapted, remixed, transformed or built upon. (https://creativecommons.org/ licenses/by-nc-nd/4.0/)

Thieme Medical and Scientific Publishers Pvt. Ltd., A-12, 2nd Floor, Sector 2, Noida-201301 UP, India 
2 Estimation of Serum Amylase Level in Acute Organophosphorus Poisoning Patil et al.

assay to measure butyrylcholinesterase activity in plasma (or acetyl cholinesterase in whole blood). However, the results of such assays are rarely available in time to affect clinical decision making. Their importance is for guidance of clinical research; understanding of their limitations is essential for interpretation of studies involving individual pesticides and specific interventions. The absence of specific laboratory tests prompts for a clinically based prognostic system. $^{3}$

The pathogenesis of pancreatic change after OP intoxication was considered to be pancreatic ductal hypertension and stimulation of exocrine pancreatic secretion. The elevation of serum amylase is not highly specific for pancreatic disease. Serum amylase may be elevated secondary to various disorders including salivary gland disease. We can speculate that the hypersalivation commonly observed in OP poisoning caused elevated serum amylase of salivary origin, because hypersalivation can cause elevated serum amylase that consisted exclusively of salivary pattern. This may be due to the fact that acute pancreatitis is caused by excessive cholinergic stimulation of pancreas by OP compounds. ${ }^{4,5}$

Prompt recognition and aggressive management of acute intoxication are essential to minimize the morbidity and mortality from these potentially lethal compounds. Hence, the present study was undertaken to know the prognosis and outcome of OP poisoning patients and to find out the better modality of outcome prediction in patients admitted to the rural the hospital and to evolve the guidelines for the healthcare providers so that the patients can be evaluated in terms of severity of poisoning. In this study, we had tried to analyze serum amylase level in acute OP poisoning and to correlate clinical outcome of the patients.

\section{Methods}

In this cross-sectional study, we had enrolled 100 cases that had history of exposure to OP compounds, as mentioned by the patients themselves or relatives, the transferring doctor or the OP compound bottle or container. Patients with history of alcohol consumption, gall stone disease, and malignancy of pancreas were excluded. The study was planned after approval from institutional ethical committee [DMIMS(DU)/IEC/2017-18/4077].

Serum cholinesterase estimation was done by kinetic propionyl thiocholine method by using SL 244 double-beam ultraviolet-visible (UV-VIS) spectrophotometer. It is used for the in vitro quantitative determination of cholinesterase in human serum. Serum amylase estimation was done by kinetic 2-chloro 4-nitrophenyl $\alpha$ D-maltotrioside (CNPG-3) method using SL 244 double-beam UV-VIS spectrophotometer

Material was procured from Fortress diagnostics CNPG-3 (liquid stable).

The Peradeniya organophosphorus poisoning (POP) scale has identified clinical parameters that can grade severity without laboratory investigations. Each POP scale parameter is assessed on a 3-point scale, varying from 0 to 2. In addition, a score of 1 is added for the presence of convulsions, making
Table 1 POP scale

\begin{tabular}{|l|l|}
\hline Parameter & Score \\
\hline 1. Miosis & \\
\hline -Pupil size $>2 \mathrm{~mm}$ & 0 \\
\hline -Pupil size $\leq 2 \mathrm{~mm}$ & 1 \\
\hline -Pupils pin-point & 2 \\
\hline 2. Fasciculation & \\
\hline -None & 0 \\
\hline -Present but not generalized or continuous & 1 \\
\hline -Generalized and continuous & 2 \\
\hline 3. Respiration & \\
\hline -Respiratory rate $\leq 20 /$ min & 0 \\
\hline -Respiratory rate $>$ 20/min & 1 \\
\hline -Respiratory rate $>20 /$ min with central cyanosis & 2 \\
\hline 4. Bradycardia & \\
\hline -Pulse rate $>60 /$ min & 0 \\
\hline -Pulse rate 41-60/min & 1 \\
\hline -Pulse rate $\leq 40 /$ min & 2 \\
\hline 5. Level of consciousness & 1 \\
\hline -Conscious and rational & 2 \\
\hline -Impaired and responds to verbal command & 11 \\
\hline $\begin{array}{l}\text {-Impaired and does not respond to verbal } \\
\text { command (add 1 if convulsion present) }\end{array}$ & \\
\hline Total score & 2 \\
\hline
\end{tabular}

Abbreviation: POP, Peradeniya organophosphorus poisoning.

the maximum possible score 11; poisoning can then be graded as mild (score $1-3$ ), moderate (score $4-7$ ), or severe (score 8-11) as shown in - Table $\mathbf{1}^{6}$

\section{Statistical Analysis}

Statistical analysis was done by using descriptive and inferential statistics using chi-squared test, Student's unpaired $t$ test, Pearson's correlation coefficient, sensitivity and specificity, and receiver operating characteristic (ROC) curve; the software used in the analysis were SPSS 22.0 version, EPIINFO 6.0 version, and Graph Pad Prism 6.0 version; and $p<0.05$ is considered as level of significance.

Chi-squared test is used for comparing frequencies, Student's unpaired $t$-test is used for comparing mean, Pearson's correlation coefficient is used for association of two quantitative data, and ROC curve is used to find area under the curve. Confusion matrix is used to assess the better specificity and sensitivity for predicting the better outcome.

\section{Results}

In present study of 100 patients, mean age of the patient was $31.78 \pm 11.66$ (14-65 years), out of which $72(72 \%)$ were males and 28 (28\%) were females. All the baseline characteristics are shown in - Table 2 . The mean serum amylase level 
Table 2 Baseline characteristics of study population

\begin{tabular}{|c|c|c|}
\hline $\begin{array}{l}\text { Baseline } \\
\text { characteristics }\end{array}$ & $\begin{array}{l}\text { No. of patients/ } \\
\text { mean } \pm \text { SD }\end{array}$ & $\begin{array}{l}\text { Percentage/ } \\
\text { range }\end{array}$ \\
\hline Age $(y)$ & $31.78 \pm 11.66$ & $14-65$ \\
\hline \multicolumn{3}{|l|}{ Gender } \\
\hline Male & 72 & $72 \%$ \\
\hline Female & 28 & $28 \%$ \\
\hline Duration of stay $(d)$ & $6.59 \pm 6.12$ & $1-28$ \\
\hline \multicolumn{3}{|l|}{ Occupation } \\
\hline Farmer & 30 & $30 \%$ \\
\hline Housewife & 19 & $19 \%$ \\
\hline Laborer & 22 & $22 \%$ \\
\hline Service & 21 & $21 \%$ \\
\hline Student & 8 & $8 \%$ \\
\hline \multicolumn{3}{|l|}{ Route of poisoning } \\
\hline Inhalation & 10 & $10 \%$ \\
\hline Oral & 90 & $90 \%$ \\
\hline \multicolumn{3}{|l|}{ Mode of contact } \\
\hline Accidental & 10 & $10 \%$ \\
\hline Suicide & 90 & $90 \%$ \\
\hline \multicolumn{3}{|c|}{ Time lag between exposure and treatment } \\
\hline$\leq 3 \mathrm{~h}$ & 72 & 72 \\
\hline $4-6 h$ & 20 & 20 \\
\hline $7-9 h$ & 5 & 5 \\
\hline$\geq 10 \mathrm{~h}$ & 3 & 3 \\
\hline GCS score & $12.49 \pm 2.80$ & $5-15$ \\
\hline Serum amylase (U/L) & $376.03 \pm 238.18$ & $52-1100$ \\
\hline Serum Ach (IU/L) & $2718.84 \pm 754.86$ & $1050-4968$ \\
\hline Ventilation support & 23 & $23 \%$ \\
\hline Intermediate support & 23 & $23 \%$ \\
\hline POP score & $4.31 \pm 3.05$ & $1-11$ \\
\hline
\end{tabular}

Abbreviations: GCS, Glasgow coma scale; POP, Peradeniya organophosphorus poisoning; SD, standard deviation.

in discharge patient was $335.40 \pm 192.45$ and in patients who died was $843.37 \pm 22.60$. It was significant to predict the outcome ( $t$-value $7.07, p$-value 0.0001 , statistically significant $[\mathrm{S}]$ ). Hyperamylasemia is seen in all the cases shown in - Table 3.

The Pearson's correlation coefficient between the two biochemical indicators serum cholinesterase and serum
Table 3 Comparison of serum amylase level with outcome

\begin{tabular}{|l|l|l|l|l|l|}
\hline Outcome & $\boldsymbol{n}$ & Mean & SD & SEM & $t$-Value \\
\hline Discharge & 92 & 335.40 & 192.45 & 20.06 & $\begin{array}{l}7.07 \\
p=0.0001, S\end{array}$ \\
\hline Death & 8 & 843.37 & 22.60 & 78.70 & \\
\hline
\end{tabular}

Abbreviations: SD, standard deviation; SEM, standard error mean.

amylase shows significant negative correlation ( $r$-value 0.537, $p$-value $0.0001, S$ ) as shown in - Table 4. Pearson's correlation coefficient shows a negative correlation between Glasgow coma scale and serum amylase, but it was significant in predicting the outcome ( $r$-value $0.534, p$-value $0.0001, S$ ) as shown in $\mathbf{- T a b l e ~ 5}$. Serum amylase level was significant to predict outcome ( $t$-value 4.091, $p$-value 0.0001 , $S$ ); serum amylase levels were found to be high in patients who died as compared with discharged patients; it was significant enough to predict the outcome of the OP poisoning as shown in - Table 6.

It shows a statistical significance with the poor outcome of the patient ( $t$-value 6.66, $p$-value $0.0001, S$ ).

Sensitivity of serum amylase level in our study was found to be $91.3 \%$ and specificity of serum amylase in our study was found to be $100 \%$ as shown in - Fig. 1 .

\section{Discussion}

In our study, all patients of OP poisoning showed hyperamylasemia but higher levels in nonsurvivors than survivors. This may be due to the fact that acute pancreatitis is caused by excessive cholinergic stimulation of pancreas by OP compounds. ${ }^{4}$ Various other study had similar results. ${ }^{7,8}$

High incidence of poisoning was observed in farmers as compared with patient in other occupation. This finding was consistent with the findings of Badiger in which $31.2 \%$ patients were farmers, ${ }^{9}$ while in Thunga et al study, $45 \%$ patients were from agriculture field. ${ }^{10}$ In our study, $90 \%$ patients consumed OP orally, while $10 \%$ patients were exposed to poisoning by inhalation route. Majority (90\%) of patients consumed poison with suicidal intention, while $10 \%$ patients consumed poison accidentally. Percentage of death was higher in patient who got late treatment. This finding was consistent with findings of other authors like Akdur et al. ${ }^{11}$

Twenty-three patients who were ventilated in intermediate syndrome had mean serum amylase level of $618.17 \pm 245.31$, as compared with 77 patients with nonventilator support had mean serum amylase level of $303.71 \pm 182.8$ ( $t$-value $6.66, p$-value $0.0001, \mathrm{~S}$ ). Study by

Table 4 Correlation of serum acetylcholinesterase with serum amylase

\begin{tabular}{|l|l|l|l|l|l|}
\hline & Mean & SD & $n$ & Correlation “ $r$ ” & $p$-Value \\
\cline { 1 - 4 } Serum acetylcholinesterase & $2,718.84$ & 754.86 & 100 & -0.537 & $0.0001, S$ \\
\cline { 1 - 3 } Serum amylase & 376.03 & 238.18 & 100 & & \\
\hline
\end{tabular}

Abbreviation: SD, standard deviation.

$r$ signifies Pearson's correlation coefficient. S signifies statistically significant. 
4 Estimation of Serum Amylase Level in Acute Organophosphorus Poisoning Patil et al.

Table 5 Correlation of GCS score with serum amylase

\begin{tabular}{|l|l|l|l|l|l|}
\hline & Mean & SD & $n$ & Correlation “ $r$ ” & $p$-Value \\
\cline { 1 - 4 } GCS score & 12.49 & 2.80 & 100 & -0.534 & $0.0001, S$ \\
\cline { 1 - 3 } Serum amylase & 376.03 & 238.18 & 100 & & \\
\hline
\end{tabular}

Abbreviations: GCS, Glasgow coma scale; SD, standard deviation.

$r$ signifies Pearson's correlation coefficient. S signifies statistically significant.

Table 6 Multivariate regression analysis

\begin{tabular}{|c|c|c|c|c|c|}
\hline \multirow[t]{2}{*}{ Model } & \multicolumn{2}{|c|}{$\begin{array}{l}\text { Unstandardized coef- } \\
\text { ficients }\end{array}$} & Standardized coefficients & \multirow[t]{2}{*}{$t$-Value } & \multirow[t]{2}{*}{$p$-Value } \\
\hline & $\beta$ & SE & $\beta$ & & \\
\hline Outcome & 0.931 & 0.266 & - & - & - \\
\hline Serum amylase & 0.000 & 0.000 & 0.417 & 4.091 & $0.0001, \mathrm{~S}$ \\
\hline Serum acetylcholinesterase & -0.0001 & 0.000 & -0.053 & 0.519 & $0.605, \mathrm{NS}$ \\
\hline GCS score & 0.003 & 0.012 & 0.032 & 0.250 & $0.803, \mathrm{NS}$ \\
\hline Intermediate syndrome & -0.064 & 0.107 & -0.099 & 0.595 & $0.553, \mathrm{NS}$ \\
\hline POP score & 0.022 & 0.013 & 0.246 & 1.780 & 0.078 , NS \\
\hline
\end{tabular}

Abbreviations: GCS, Glasgow coma scale; POP, Peradeniya organophosphorus poisoning; SE, standard error. S signifies statistically significant; NS signifies not significant.

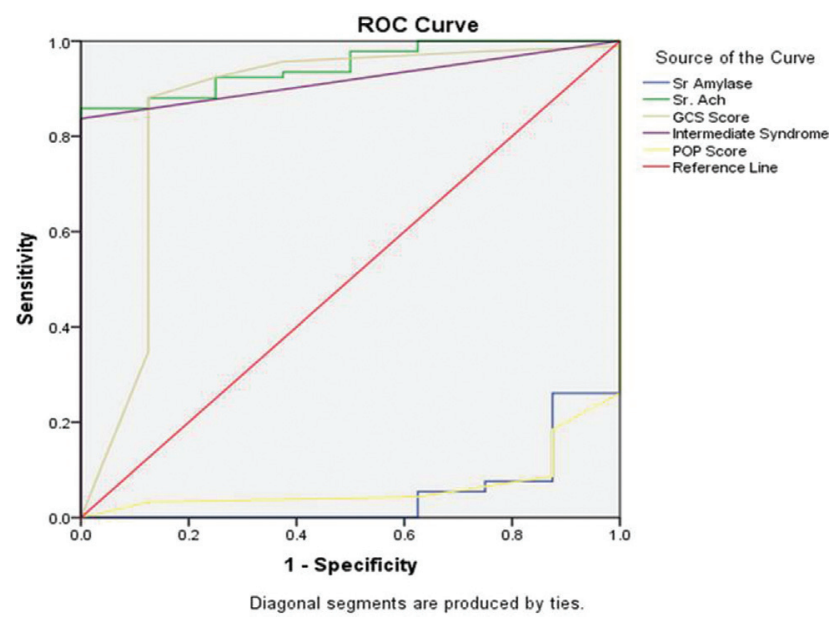

Fig. 1 ROC curve showing sensitivity and specificity of serum amylase

Lin et al also showed similar result where they found that mean amylase level of the patient group with respiratory failure was significantly higher than those without respiratory failure $(436.1 \pm 87.1$ vs. $181.3 \pm 29.6, p<0.01) .{ }^{12}$

Our study shows no statistical significance with duration of stay with serum amylase level of the patient. The Pearson's correlation coefficient between the two biochemical indicators serum cholinesterase and serum amylase shows significant negative correlation ( $r$-value $0.537, p$-value $0.0001, S$ ). Similar results were found in study of Mohite et al in which the Pearson's coefficient correlation between serum cholinesterase and serum amylase was negative ( $r$-value 0.243 , $p$-value $0.012, S)$ with mean the value of 2,636.16 \pm 935.08 and $572.20 \pm 226.54 \mathrm{IU}$, respectively. ${ }^{13}$
In this study, mean serum cholinesterase level for the patients with mild POP scale was 2,996.13 \pm 636.36 , for moderate POP scale it was $2,749.20 \pm 551.77$, and for severe scale it was $1,855.40 \pm 614.68$. By using one-way analysis of variance (ANOVA) statistically significant variation was found in serum cholinesterase level among POP scale $(F=25.71, p$-value $=0.0001)$.

Mean serum amylase level for the patients with mild POP scale was $317.55 \pm 184.54$, for moderate POP scale it was $310.02 \pm 247.77$ and for severe scale it was $594.70 \pm 264.26$. By using one-way ANOVA, statistically significant variation was found in serum amylase level among POP. This concludes that severity of OP poisoning according to POP scale significantly correlates with serum amylase and serum acetylcholinesterase. This finding is similar to study conducted by Senanayake and Karalliedde. ${ }^{6}$

\section{Conclusion}

Serum amylase level can predict prognosis in OP poisoning patients. Serum amylase level also shows significant correlation with clinical outcome in OP poisoning.

Conflict of Interest

Nil.

\section{References}

1 Narang U, Narang P, Gupta O. Organophosphorus poisoning: a social calamity. J Mahatma Gandhi Institute of Medical Sciences. 2015;20(01):46-51

2 Kumar SV, Fareedullah M, Sudhakar Y, Venkateswarlu B, Kumar EA. Current review on organophosphorus poisoning. Arch Appl Sci Res 2010;2(04):199-215 
3 Eddleston M, Buckley NA, Eyer P, Dawson AH. Management of acute organophosphorus pesticide poisoning. Lancet 2008;371 (9612):597-607

4 Ahmed A, Begum I, Aquil N, Atif S, Hussain T, Vohra EA. Hyperamylasemia and acute pancreatitis following organophosphate poisoning. Pak J Med Sci 2009;25(06):957-961

5 Kumar S, Agrawal S, Raisinghani N, Khan S. Leukocyte count: a reliable marker for the severity of organophosphate intoxication? J Lab Physicians 2018;10(02):185-188

6 Senanayake N, Karalliedde L. Neurotoxic effects of organophosphorus insecticides. An intermediate syndrome. N Engl J Med 1987;316(13):761-763

7 Sumathi ME, Kumar SH, Shashidhar KN, Takkalaki N. Prognostic significance of various biochemical parameters in acute organophosphorus poisoning. Toxicol Int 2014;21(02):167-171

8 Salame RN, Wani AS. Study of serum amylase levels in organophosphate poisoning. Int J Biol Adv Res 2017;8:5
9 Badiger S. Study of Serum Amylase and Serum Cholinesterase in Organophosphorus Poisoning. 2016;5(02):49-56

10 Thunga G, Sam KG, Khera K, Sureshwar P, Sagar SV. Evaluation of incidence, clinical characteristics and management in organophosphorus poisoning patients in a tertiary care hospital. J Toxicol Environmen Health Sci 2010;2(05):73-76

11 Akdur O, Durukan P, Ozkan S, et al. Poisoning severity score, Glasgow coma scale, corrected QT interval in acute organophosphate poisoning. Hum Exp Toxicol 2010;29(05): 419-425

12 Lin C-L, Yang C-T, Pan K-Y, Huang C-C. Most common intoxication in nephrology ward organophosphate poisoning. Ren Fail 2004; 26(04):349-354

13 Anjankar MP. Organophosphorus poisoning: prognostic value of GCS score \& other clinical indicators in assessing the final outcome. J Indian Forensic Med 2018;40(02):197-205 